\title{
Determination of Odorants in Varietal Wines from International Grape Cultivars (Vitis vinífera) Grown in NW Spain
}

\author{
M. Vilanova ${ }^{1 *}$, Z. Genisheva ${ }^{2}$, M. Graña ${ }^{3}$ and J.M. Oliveira ${ }^{2}$ \\ (1) Misión Biológica de Galicia (CSIC), Pontevedra, Spain \\ (2) IBB-Institute for Biotechnology and Bioengineering, Centre of Biological Engineering, Minho University, 4710-057 Braga, \\ Portugal \\ (3) EVEGA, Station of Viticulture and Oenology of Galicia, Ribadumia, Spain
}

Submitted for publication: February 2013

Accepted for publication: April 2013

Key words: Wine volatile compounds, Vitis vinifera, NW Spain

\begin{abstract}
This work was carried out to investigate the odorants found in ten varietal wines from different international grape cultivars (Merlot, Cabernet Sauvignon, Pinot noir, Tempranillo, Sauvignon blanc, Riesling, Chardonnay, Pinot gris, Pinot blanc and Gewürztraminer) grown in northwest Spain. Monoterpenes, alcohols, fatty acids, ethyl esters, acetates and volatile phenols were determined by gas chromatographymass spectrometry (GC-MS). The results showed that Gewürztraminer white wines had the highest concentration of volatile compounds $(35.7 \mathrm{mg} / \mathrm{L})$. Monoterpenes, linalool, terpineol, citronellol and nerol were detected only in Riesling and Gewürztraminer white wines. In the red wines, Cabernet Sauvignon followed by Merlot wines showed the highest concentration of total volatile composition (55.60 mg/L and $50.90 \mathrm{mg} / \mathrm{L}$ respectively), characterised by a higher concentration of alcohols. Based on the individual odour threshold, white Gewürztraminer and red Pinot noir wines showed the highest total OAV value. ANOVA has shown significant differences among wines. Principal component analysis performed a grouping of the monovarietal wines - Sauvignon blanc-Pinot blanc-Riesling and Pinot gris gris-Gewürztraminer in the white wines, and Cabernet Sauvignon-Tempranillo in the red wines.
\end{abstract}

\section{INTRODUCTION}

Flavour composition plays a significant role in the quality of a wine. The flavour of wine is composed of volatile compounds, which are responsible especially for the aroma (Schreier, 1979). More than 800 volatile compounds have been identified in wines, with a concentration range varying from hundreds of $\mathrm{mg} / \mathrm{L}$ to the $\mu \mathrm{g} / \mathrm{L}$ or $\mathrm{ng} / \mathrm{L}$ level (Li, 2006). It is well known that the chemical compounds responsible for wine aroma are mainly alcohols, esters, volatile fatty acids, aldehydes and ketones, of which esters are particularly important (Rapp \& Mandery, 1986). In addition, these mentioned compounds, e.g. terpenols and $\mathrm{C}_{13}$ norisoprenoids, typically contribute to the character of wines.

Many authors have studied the volatile composition of different grapes and wines (Gunata et al., 1985; Rapp \& Mandery, 1986; Etievant, 1991; Ferreira et al., 2000; Oliveira et al., 2004; Swiegers \& Pretorius, 2005; Vilanova \& Sieiro, $2006,2007)$. The amount of wine volatile compounds can be influenced by several factors, such as grape variety, the degree of ripeness, growing climate, fermentation conditions, and winemaking and ageing practices (Gomez et al., 1994; Rapp, 1998; Bueno et al., 2003; Oliveira et al., 2006). International varieties, considered the most cultivated varieties in the world (Robinson, 2006), have been studied in relation to different aspects during the last number of years. Recently, several authors studied wine volatile compounds from international cultivars grown in different geographic areas, namely Cabernet Sauvignon from China, California and Brazil (Falcao et al., 2008; Preston et al., 2008; Tao et al., 2008; Jiang \& Zhang, 2010), Sauvignon blanc from New Zealand, France and Australia (Berna et al., 2009; Lund et al., 2009), Chardonnay from Croatia and China (Hejavec et al., 2007; Preston et al., 2008; Falcao et al., 2008; Berna et al., 2009; Jiang \& Zhang 2010), Tempranillo, Cabernet Sauvignon and Merlot from Spain (Ferreira et al., 2000), and others. These studies have attempted to characterise the different wines from different terroir to show the influence of geographic area on wine composition, thus showing the versatility of these grape varieties.

The aim of this work was to define the major volatile compounds of young wines produced from international cultivars (Merlot, Cabernet Sauvignon, Tempranillo, Pinot noir, Sauvignon blanc, Riesling, Chardonnay, Pinot gris, Pinot blanc and Gewürztraminer) in Galicia (NW Spain) and to identify the most odour-active compounds.

*Corresponding authors: E-mail: mvilanova@mbg.csic.es

Aknowledgements: The authors would like to thank the technical staff of EVEGA (Xunta de Galicia, Spain) for the production of the cultivars and the elaboration of the wines. 


\section{MATERIALS AND METHODS \\ Grape samples}

Ten international Vitis vinifera grape cultivars - four red (Merlot, Cabernet Sauvignon, Tempranillo and Pinot noir) and six white (Sauvignon blanc, Riesling, Chardonnay, Pinot gris, Pinot blanc and Gewürztraminer) from NW Spain were considered in this study. The different cultivars, from the 2008 vintage, were grown in the same conditions in the vineyards of the Station of Viticulture and Enology (EVEGA) in Galicia. The must composition of the different cultivars is shown in Table 1 . Total acidity, $\mathrm{pH}$, density, reducing sugar and potential alcohol were analysed in the musts before fermentation according to official OIV (1990) methods.

\section{Must fermentation}

The wines analysed in this study were elaborated in the EVEGA winery. White and red wines were produced in $16 \mathrm{~L}$ glass vessels, in triplicate. Before fermentation, sulphur dioxide $(4 \mathrm{~g} / \mathrm{hL})$ and ascorbic acid $(5 \mathrm{~g} / \mathrm{hL})$ were added to the musts. The wines were elaborated using standard winemaking practices. The fermentation of white cultivars was conducted by a yeast strain from the Institut Enologique de Champagne, Saccharomyces cerevisiae var. bayanus, IOC-18-2007 (20 g/hL) at $18^{\circ} \mathrm{C}$. Saccharomyces cerevisiae var. cerevisiae $71 \mathrm{~B}$ from Lalvin, INRA $(30 \mathrm{~g} / \mathrm{hL})$ at $28^{\circ} \mathrm{C}$ was used to ferment musts from the red cultivars. Malolactic fermentation was performed with the red wines. After fermentation the wines were filtered and transferred to $0.75 \mathrm{~L}$ bottles. The bottles were stopped with cork and stored at $16^{\circ} \mathrm{C}$ until analysis.

Total acidity, density, ethanol, tartaric, acetic and malic acids, and the Folin-Ciocalteau index were determined after fermentation. All analyses were performed in triplicate according to official OIV (1990) methods.

\section{Volatile compound extraction and analysis}

All solvents were analytical grade and further purified. In a $10 \mathrm{~mL}$ culture tube (Pyrex, ref. 1636/26MP), $8 \mathrm{~mL}$ of wine, $2.4 \mu \mathrm{g}$ of internal standard (4-nonanol, Merck ref. 818773, Darmstadt, Germany) and a magnetic stir bar (22.2 mm x $4.8 \mathrm{~mm}$ ) were added. Extraction of volatiles was done by stirring the sample with $400 \mu \mathrm{L}$ of dichloromethane (Merck, ref. 1.06054; Darmstadt, Germany), according to the method of Oliveira et al. (2006). After cooling at $0^{\circ} \mathrm{C}$ for $10 \mathrm{~min}$, the magnetic stir bar was removed and the organic phase was detached by centrifugation $\left(\mathrm{RCF}=5118,5 \mathrm{~min}, 4^{\circ} \mathrm{C}\right)$ and the extract was recovered into a vial, using a Pasteur pipette. The aromatic extract $(200 \mu \mathrm{g} / \mathrm{L})$ was dried with anhydrous sodium sulphate (Merck, ref. 1.06649; Darmstadt, Germany) and placed in a new vial. Extractions of volatile compounds from each of the respective wines were performed in triplicate.

A Chrompack CP-9000 gas chromatograph equipped with a split/splitless injector and a flame ionisation detector (FID) with a capillary column, coated with CP-Wax $52 \mathrm{CB}$ (50 m x 0.25 mm i.d., $0.2 \mu \mathrm{m}$ film thickness, Chrompack), was used. The temperature of the injector and detector were both set to $250^{\circ} \mathrm{C}$. The oven temperature was held at $40^{\circ} \mathrm{C}$ for $5 \mathrm{~min}$, then programmed to rise from $40^{\circ} \mathrm{C}$ to $235^{\circ} \mathrm{C}$, at $3^{\circ} \mathrm{C}$ $\mathrm{min}^{-1}$, and then finally programmed from $235^{\circ} \mathrm{C}$ to $255^{\circ} \mathrm{C}$, at $5^{\circ} \mathrm{C} \mathrm{min}^{-1}$. The carrier gas was helium 55 (Praxair; Teruel, Spain) at $103 \mathrm{kPa}$, and the split vent was set to $13 \mathrm{~mL} / \mathrm{min}$. Each $3 \mu \mathrm{L}$ extract was injected in the splitless mode (vent time $15 \mathrm{~s})$. Quantification of volatiles, as 4-nonanol equivalents, was performed with Varian MS Workstation version 6.6 by comparing the retention indices with those of pure standard compounds and confirming these by GC-MS (Oliveira et al., 2008).

\section{Odour activity value}

The odour activity value (OAV) was determined to evaluate the contribution of a chemical compound to the aroma of a wine. OAV is a measure of the importance of a specific compound to the odour of a sample. OAV $>1$ indicates possible contribution to the wine aroma. This was calculated as the ratio between the concentration of the individual compound and the perception threshold found in the literature (Etievant, 1991; Ferreira et al., 2000; Francis \& Newton, 2005; Vilanova et al., 2009).

\section{Statistical analyses}

The data analyses were performed using XLstat-Pro (Addinsoft). The data were subjected to one-way analysis of

TABLE 1

General chemical parameters of red and white musts from international cultivars

\begin{tabular}{lccccc}
\hline Musts & \multicolumn{5}{c}{ Chemical parameters } \\
\hline Red varieties & Total acidity/(g/L) & $\mathrm{pH}$ & Density/(g/mL) & Reducing sugar/(g/L) & Probably degree/(\% v/v) \\
\hline Cabernet-sauvignon & 5.02 & 3.57 & 1.089 & 212.0 & 12.47 \\
Pinot noir & 5.62 & 3.75 & 1.100 & 238.7 & 14.04 \\
Tempranillo & 4.50 & 3.58 & 1.087 & 206.7 & 12.16 \\
Merlot & 4.50 & 3.69 & 1.097 & 232.4 & 13.67 \\
\hline White varieties & & & & 235.8 & 13.87 \\
\hline Chardonnay & 4.15 & 3.29 & 1.098 & 187.4 & 11.02 \\
Pinot blanc & 5.47 & 3.44 & 1.080 & 238.5 & 14.03 \\
Pinot gris & 4.50 & 3.61 & 1.100 & 177.3 & 10.43 \\
Riesling & 6.67 & 3.15 & 1.076 & 225.6 & 13.27 \\
Sauvignon blanc & 7.20 & 3.30 & 1.094 & 231.4 & 13.61 \\
Gewürztraminer & 2.84 & 3.90 & 1.097 & & \\
\hline
\end{tabular}


variance (ANOVA). The mean differences between cultivars were calculated according to the least significant difference from Fisher's test (LSD), with a confidence interval of 95\%. Principal component analysis (PCA) was applied to the wine volatile compounds to study the possible grouping of the varietal wines to investigate correlations between cultivars and volatile compounds.

\section{RESULTS AND DISCUSSION \\ Classical parameters}

Table 1 shows the chemical composition of the must from international cultivars. In the red cultivars, Pinot noir must showed the highest values for the chemical parameters analysed. In the white cultivars, Pinot gris and Chardonnay musts showed the highest sugar content, thus high technology maturity was presented by these two cultivars. The total acidity was higher for Sauvignon blanc and Riesling musts, while the lowest total acidity was found for Gewürztraminer $(2.84 \mathrm{~g} / \mathrm{L})$.

The general composition of the wines is showed in Table 2. In the red wines, Pinot noir and Merlot presented the highest values of ethanol $(13.5 \% \mathrm{v} / \mathrm{v}$ and $13.1 \% \mathrm{v} / \mathrm{v}$ respectively) and the lowest values of tartaric acid. However, Tempranillo and Merlot showed the lowest total acidity values. Similar values for the Folin-Ciocalteau index were found among the wines, with the highest concentrations found in Cabernet Sauvignon (45.7) and Merlot (45.8). In the white wines, Pinot gris, Gewürztraminer and Chardonnay showed the highest ethanol concentration $(14.6 \% \mathrm{v} / \mathrm{v}, 14.3 \%$ $\mathrm{v} / \mathrm{v}$ and $14.1 \% \mathrm{v} / \mathrm{v}$ respectively). In terms of total acidity and tartaric acid, the highest values were found in Riesling wines $(6.50 \mathrm{~g} / \mathrm{L}$ and $3.8 \mathrm{~g} / \mathrm{L}$ respectively) and in Sauvignon blanc (6.70 g/L and $3.3 \mathrm{~g} / \mathrm{L}$ respectively). Sauvignon blanc also showed the highest value for malic acid $(2.0 \mathrm{~g} / \mathrm{L})$.

\section{Volatile composition of wines}

Tables 3 and 4 show the mean concentration and standard deviation of the volatile compounds determined in the white and red wines. In the white wines (Table 3), 28 volatile compounds were identified - four monoterpenes, three $\mathrm{C}_{6}$ compounds, four alcohols, eight ethyl esters and acetates, seven volatile fatty acids and two volatile phenols. Many of these volatile compounds are commonly found in wines and are derived from the grapes and the vinification process (Cliff et al., 2002). Gewürztraminer wines showed the highest concentration of volatile compounds $(35.7 \mathrm{mg} / \mathrm{L})$, represented by the highest levels of monoterpenic alcohols $(0.83 \%)$, ethyl esters and acetates $(24 \%)$, volatile fatty acids $(25.7 \%)$ and volatile phenols $(0.2 \%)$. Vitis vinifera $\mathrm{L}$. cv. Gewürztraminer is an aroma-rich grape cultivar in which terpene constituents are mainly responsible for the flavour attributes (Marais, 1987).

The results obtained from the ANOVA indicate that, of the 28 compounds quantified in the white wines, only 1-hexanol and ethyl 3-methylbutyrate did not show significant differences between the wines tested. Regarding the red wines, 22 volatile compounds were identified and quantified - three $\mathrm{C}_{6}$ compounds, three alcohols, nine ethyl esters and acetates, and seven volatile fatty acids (Table 4). Significant differences among wines were found for all the volatile compounds. Cabernet Sauvignon, followed by Merlot wines, showed the highest concentration of total volatile composition (55.60 mg/L and $50.90 \mathrm{mg} / \mathrm{L}$ respectively).

\begin{abstract}
Alcohols
Alcohols are produced mainly during yeast fermentation of sugars and yeast metabolism of amino acids, and their aroma contribution to wine is not considered to be particularly pleasant, with the exception of 2-phenylethanol (roselike aroma) (Simpson, 1979; Etievant, 1991). The alcohol chemical family was the largest volatile group in the white wines, showing values between $62.8 \%$ for Chardonnay and $49 \%$ for Gewürztraminer wine. 2-Phenylethanol was the compound that was present at the highest concentration in all white wines. This compound can be present in the grapes, but it is largely produced by wine yeast during fermentation (Quian et al., 2009). In the red wines studied, alcohols were also the largest group, showing the highest concentration in the Cabernet Sauvignon and Merlot wines, accounting for $88 \%$ and $89 \%$ of the total volatile concentration respectively.
\end{abstract}

TABLE 2

General chemical composition of wines from international red and white varieties.

\begin{tabular}{|c|c|c|c|c|c|c|c|}
\hline \multirow{2}{*}{$\begin{array}{l}\text { Wines } \\
\text { Red varieties }\end{array}$} & \multicolumn{7}{|c|}{ Chemical parameters } \\
\hline & $\begin{array}{c}\text { Total acidity/ } \\
(\mathrm{g} / \mathrm{L})\end{array}$ & $\begin{array}{l}\text { Volatile acidity/ } \\
\text { (g/L) }\end{array}$ & $\begin{array}{l}\text { Density } \\
(\mathrm{g} / \mathrm{mL})\end{array}$ & $\begin{array}{l}\text { Ethanol/ } \\
(\% \mathrm{v} / \mathrm{v})\end{array}$ & $\begin{array}{l}\text { Malic acid/ } \\
(\mathrm{g} / \mathrm{L})\end{array}$ & $\begin{array}{c}\text { Tartaric acid/ } \\
(\mathrm{g} / \mathrm{L})\end{array}$ & Folin index \\
\hline Cabernet-sauvignon & 5.00 & 0.30 & 0.993 & 11.8 & $<0.3$ & 1.9 & 45.7 \\
\hline Pinot noir & 4.60 & 0.40 & 0.992 & 13.5 & 1.3 & 1.3 & 41.3 \\
\hline Tempranillo & 3.60 & 0.40 & 0.992 & 11.6 & $<0.3$ & 1.9 & 42.5 \\
\hline Merlot & 3.90 & 0.30 & 0.992 & 13.1 & $<0.3$ & 1.8 & 45.8 \\
\hline \multicolumn{8}{|l|}{ White varieties } \\
\hline Chardonnay & 5.80 & 0.40 & 0.990 & 14.1 & 1.8 & 2.0 & - \\
\hline Pinot blanc & 5.00 & 0.30 & 0.990 & 11.6 & 1.8 & 2.4 & - \\
\hline Pinot gris & 4.40 & 0.50 & 0.988 & 14.6 & 1.6 & 1.3 & - \\
\hline Riesling & 6.50 & 0.40 & 0.991 & 11.0 & 1.2 & 3.8 & - \\
\hline Sauvignon blanc & 6.70 & 0.40 & 0.989 & 13.6 & 2.0 & 3.3 & - \\
\hline Gewürztraminer & 2.90 & 0.40 & 0.987 & 14.3 & 0.6 & 1.4 & - \\
\hline
\end{tabular}




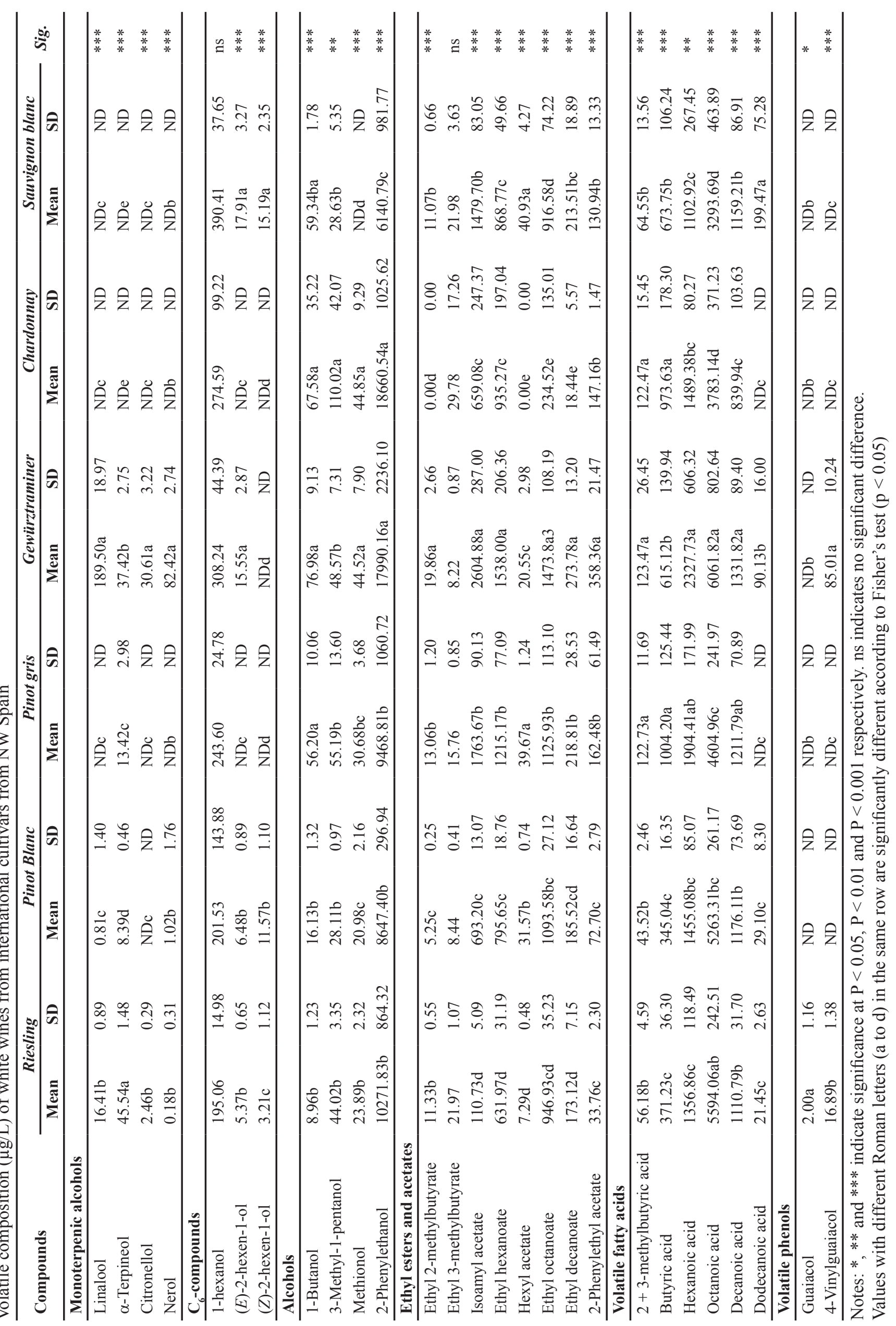




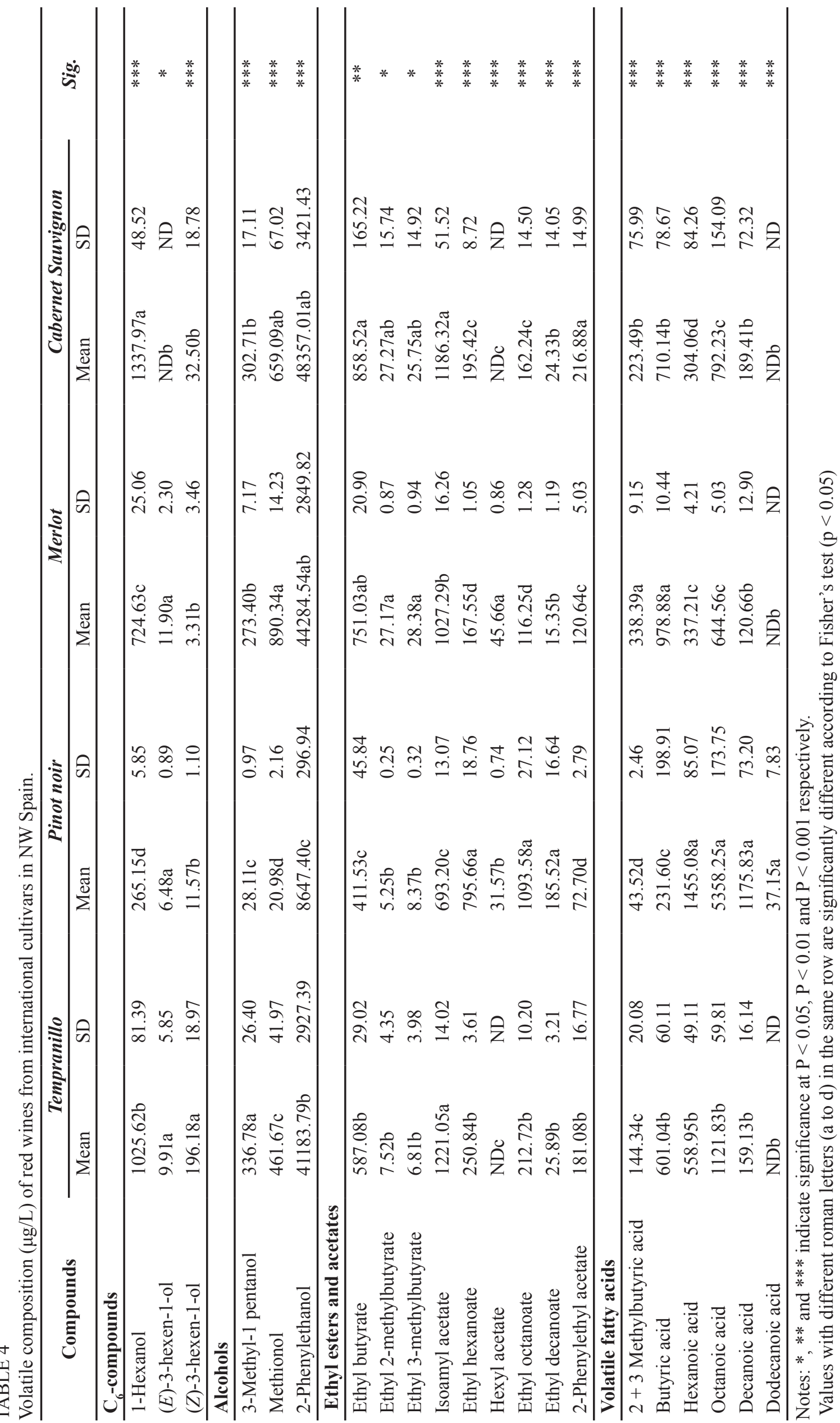


Studies performed by Tao et al. (2008) reported high values for higher alcohols and ethyl esters in Cabernet Sauvignon wines from China. 2-Phenylethanol was the compound that presented the highest concentration in all of the red wines, with the highest concentration found in Cabernet Sauvignon wines $(48.36 \mathrm{mg} / \mathrm{L})$, followed by Merlot $(44.28 \mathrm{mg} / \mathrm{L})$. Methionol was also present at a high concentration in the Merlot and Cabernet Sauvignon wines.

\section{$\mathrm{C}_{6}$ compounds}

$\mathrm{C}_{6}$ compounds showed the highest levels in Sauvignon blanc wine $(423.51 \mu \mathrm{g} / \mathrm{L})$, with the highest value for 1-hexanol (390.41 $\mu \mathrm{g} / \mathrm{L})$. This compound is known as "leaf" alcohol and has a "grassy" flavour (Berna et al., 2009). In the red wines, 1-hexanol showed high values in Cabernet Sauvignon $(1370.49 \mu \mathrm{g} / \mathrm{L})$ and Tempranillo (1231.71 $\mu \mathrm{g} / \mathrm{L})$ wines; however, 1-hexanol was only present in trace amounts in the Cabernet Sauvignon from the Loess Plateau region of China (Jiang \& Zhang, 2010). C6 compounds are partly responsible for the green and herbaceous aroma of grapes and wines (Gómez et al., 1995). High water status, especially during the later stages of ripening, could have negative effects on wine aroma. Too much water results in wine with more vegetal, bell pepper and herbaceous aroma (Quian et al., 2009). In our study, the rainfall in late September and October (the last weeks of maturity) was high, above $500 \mathrm{~mm}$, thus affecting the herbaceous character in all the red cultivars, especially the Cabernet Sauvignon wine. Cabernet Sauvignon has its origin in the Bordeaux region of France, but now is planted all over the world. Research shows that the aroma profiles of Merlot and Cabernet Sauvignon wines in Bordeaux are very close (Allen et al., 1994). The aroma of these wines is often described as fruity or floral, with roasted, wood-smoke, cooked meat nuances, and often as herbaceous, especially the wines of Cabernet Sauvignon (Allen et al., 1994). At low levels, vegetative aromas such as bell pepper or asparagus contribute to the distinctive varietal aromas of Cabernet Sauvignon and Merlot wines, and are associated with different volatile compounds (Preston et al., 2008). Other authors have also indicated that young red wines of Cabernet Sauvignon and Merlot have similar aromatic characteristics, and they concluded that differences between these varieties are quantitative rather than qualitative (Gómez et al., 1994; López et al., 1999).

\section{Monoterpenes}

Terpene compounds belong to the secondary plant constituents, of which the biosynthesis begins with acetylcoenzyme A(CoA) (Manitto, 1980). Monoterpenenic alcohols like linalool, geraniol, nerol, citronellol and $\alpha$-terpineol are known to be important compounds in grape berries, and are responsible for floral notes in the aromatic grape varieties Muscat, Riesling, Viognier, Loureiro and Gewürztraminer, as well as other varieties not usually considered to be floral, including Pinot gris and Chardonnay (Arrhenius et al., 1996; Swiegers \& Pretorius, 2005; Luan et al., 2006; Oliveira et al., 2008). In our study, the Gewürztraminer wines showed the highest concentrations of linalool, citronellol and nerol. Citronellol was only present in Riesling and Gewürztraminer white wines. Linalool is considered a very important compound, in both the free and bound form, in Gewürztraminer wines from the Maule Valley (Chile), which is classified as having a Mediterranean climate (Agosin et al., 1994). Gewürztraminer produced in the Alsace region showed differences in the levels of the three monoterpenes (cis-rose oxide, linalool, and geraniol) when compared to those from New York State, which could be attributed to differences in viticultural and oenological practices between these regions (Peter et al., 1999). Linalool, geraniol and citronellol have often been considered important contributors to the aroma of Gewürztraminer (Marais, 1987). These authors suggested that these terpenes were important to the typical character and quality of Gewürztraminer wines. $\alpha$-Terpineol showed the highest value for Riesling wines; however, terpenes have not been identified in Chardonnay and Sauvignon blanc wines and low values of these compounds were found in Pinot blanc $(10.22 \mu \mathrm{g} / \mathrm{L})$ and Pinot gris $(13.42 \mu \mathrm{g} / \mathrm{L})$ wines. Another study determined that terpenes are not considered to contribute to Chardonnay wines, or else their concentration was very low (Arrhenius et al., 1996).

\section{Ethyl esters and acetates}

Acetates and esters are formed by the reaction of acetylCoA with higher alcohols formed by the degradation of amino acids or carbohydrates (Etievant, 1991). Esters in wine mainly originate from yeast metabolism during fermentation, but some esters are also found in small amounts in the grape berry (Perestrelo et al., 2006). The yeast strain chosen for fermentation and the fermentation conditions will influence the concentration and types of esters formed (Rapp \& Mandery, 1986). Only a few esters, occurring in small quantities in grapes, contribute to the aroma of Vitis vinifera varieties. They are mainly acetates of short-chain alcohols (Swiegers \& Pretorius, 2005). The present research found significant differences in esters between among cultivars, with the exception of ethyl 3-methylbutyrate. Gewürztraminer wines showed the highest concentrations of these compounds $(6297.49 \mu \mathrm{g} / \mathrm{L})$, with the exception of hexyl acetate, followed by Pinot gris $(4554.55 \mu \mathrm{g} / \mathrm{L})$. Hexyl acetate and ethyl 2-methylbutyrate were absent from Chardonnay wines. Research on Californian Chardonnay wines showed that the fruity and floral terms were associated with 2-phenylethyl acetate (Lee \& Noble, 2003). In the red wines, ethyl butyrate, ethyl 2-methylbutyrate, ethyl 3-methylbutyrate, isoamyl acetate, ethyl hexanoate and ethyl octanoate made an important contribution to the fruity character of the wines (Meilgaard, 1975; Escudero et al., 2004; Li et al., 2008). In our study, Pinot noir showed the highest concentration of ethyl esters and acetates, with ethyl octanoate and ethyl hexanoate showing the major concentrations in this cultivar. Isoamyl acetate showed the highest concentration in Tempranillo wine. This result is in concordance with studies undertaken by Ferreira et al. (2000) on Tempranillo wine elaborated with grapes grown in a Mediterranean climate. Hexyl acetate was absent from Tempranillo and Cabernet Sauvignon.

\section{Volatile fatty acids}

Although there are many different types of acid in wine, the fatty acids are considered to be the most likely of this class 
of compounds to contribute to the aroma of wine (Etievant, 1991). Fatty acids are believed to originate primarily from yeast and bacteria biosynthesis during the fermentation stage of winemaking (Etievant, 1991). Volatile fatty acids showed the highest values for Gewürztraminer wines $(10550.09 \mu \mathrm{g} / \mathrm{L})$, followed by Pinot gris $(8848.10 \mu \mathrm{g} / \mathrm{L})$, but with the exception of butyric acid and dodecanoic acid. Dodecanoic acid was absent from Pinot gris and Chardonnay. The major compound in all white wines was octanoic acid, showing the highest concentration in Gewürztraminer wines. In the red wines, Pinot noir was characterised by high values of the volatile fatty acid family, reaching $40 \%$ of total volatile composition and characterised by high values of octanoic, decanoic and hexanoic acids. Pinot noir originated from the Burgundy region of France and has become popular in the United States of America, especially in Oregon. It exhibits distinct red fruity aromas, showing particularly odours of small-stone fruits (plum and cherry). However, the grape requires a long, cool growing season to develop the right flavour attributes (Fang \& Quian, 2006). Dodecanoic acid was absent from all wines with the exception of Pinot noir.

\section{Volatile phenols}

Volatile phenols bearing a vinyl radical and an ethyl radical are abundant in white and red wine respectively. Volatile phenols are formed from phenolcarboxylic acids (ferulic and coumaric) by sequential decarboxylation and reduction of the vinyl group to the ethyl group. Wine yeasts are incapable of reducing the vinyl group actively (Shimizu et al., 1982).

Concerning the volatile phenols, only Riesling wines showed clear signs of guaiacol $(2 \mu \mathrm{g} / \mathrm{L})$. Similar concentrations of guaiacol have been found in Australian Riesling wines (0.2 to $2 \mu \mathrm{g} / \mathrm{L})$ (Smyth et al., 2008). 4-Vinylguaiacol was only present in the Riesling and Gewürztraminer wines (16,89 and $85.01 \mu \mathrm{g} / \mathrm{L}$ respectively). 4-Vinylguaiacol has been detected as an active odorant in Rhine Riesling wine (Komes et al., 2006), Niagara Peninsula (Bowen \& Reynolds, 2012) and Australian Riesling wines (Smyth et al., 2008). This compound is responsible for the spice and smoke notes in wines from the Gewürztraminer cultivar (Versini et al., 1999). Volatile phenols were not detected in the red wines.

\section{Principal component analysis (PCA)}

The principal component analyses (PCA) performed on the wine volatile concentration is shown in Fig. 1. PCA provides a visual representation of the relationship between the wines based on their volatile composition.

With regard to the white wines (Fig. 1A), the first two principal components (PC1 and PC2) accounted for 69.19\% of the variance $(42.26 \%$ and $26.93 \%$ respectively). The first component (PC1) was characterised by a higher concentration of nerol, linalool, citronellol, ethyl 2-methylbutyrate, isoamyl acetate, ethyl hexanoate, 2-phenylethyl acetate, ethyl hexanoate, hexanoic acid and 4-vinylguaiacol in the positive loading. For the second principal component (PC2), the volatile compounds 3-methyl-1-pentanol, methionol and 2-phenylethanol showed positive loading. The resulting graphs illustrate relationships between wines. A good separation among four wine groups was observed in the PCA. The first group, situated on the negative side of PC1, is formed by the Riesling, Pinot blanc and Sauvignon blanc wines. A second group is formed by the Pinot gris and Gewürztraminer wines, located on the positive side of PC1 and PC2. Finally, a third, isolated group of Chardonnay wines is located at high and positive values in PC2.

The PCA performed on the red wine volatile compounds is shown in Fig. 1B. The two principal components (PC1 and PC2) accounted for $90.14 \%$ of the variance $(72.35 \%$ and $17.78 \%$ respectively). The first principal component (PC1) was characterised by higher concentrations of ethyl hexanoate, ethyl octanoate, hexanoic acid, decanoic acid and dodecanoic acid in the positive loading of PC1, and 1-hexanol, 3-methyl-1-pentanol, methionol, 2-phenylethanol, ethyl butyrate, isoamyl acetate, $2+3$ methylbutyric acid and butyric acid in the negative loading of the same axis. The second principal component (PC2) showed hexyl acetate in the positive loading and (Z)-3-hexen-1-ol in the negative loading of the same axis. Three groups can be visualised in the PCA: Cabernet Sauvignon and Tempranillo formed one group on the negative side of $\mathrm{PC} 1$; a second group, formed by Merlot wines, is also located on the negative side of the same axis in PC1. The third group was formed by Pinot noir, on the positive side of the PC1 and PC2 axes.

\section{Odour activity value (OAV)}

In order to assess the influence of the compounds studied on overall wine aroma, the odour activity value (OAV) was calculated by dividing the concentration of each compound by its perception threshold. Only the compounds with an OAV greater than 1 contribute individually to the wine aroma (Guth, 1997). When the OAV of a particular compound is less than 1, however, it might contribute to the aroma of a wine because of the additive effect of similar compounds (similar structure or odour) (Francis \& Newton, 2005).

The odour descriptor, OAV and threshold for each compound analysed is listed in Table 5. Fifteen volatile compounds (54\%) identified in the white wines and fourteen in the red wines $(64 \%)$ presented an $\mathrm{OAV}>1$, contributing to the aroma of the wines analysed. Gómez-Miguez et al. (2007) found, for Zalema wines, that only $32 \%$ of the quantified volatile components were present at concentrations higher than their corresponding threshold values $(\mathrm{OAVs}>1)$. Other authors (López et al., 1999; Escudero et al., 2004; Jiang \& Zhang, 2010) have shown similar results in other young white and rosé wines. Ethyl-3-methylbutyrate, isoamyl acetate, ethyl hexanoate, butyric acid, hexanoic acid and octanoic acid contributed to the wine aroma of all the white cultivars studied. The Pinot gris and Sauvignon blanc wines had the same odorants with OAVs above 1, and Gewürztraminer contained the most odour-active compounds, suggesting it to be the white wine with the most complex flavour. The floral character was represented by only two compounds with an $\mathrm{OAV}>1$. Linalool only contributed to the floral character of the Gewürztraminer wines, and 2-phenylethanol only seemed to contribute to the same character in the Chardonnay, Riesling and Gewürztraminer wines, because their concentrations were above the odour threshold.

In the red wines, Merlot and Cabernet Sauvignon showed the same odorants with OAVs $>1$, and the highest OAV for 
both wines was ethyl butyrate. The most intense odorants in Merlot and Cabernet Sauvignon wines produced in California and Australia are 3-methyl-1-butanol, 3-hydroxy2-butanone, octanal, ethyl hexanoate, 2-methoxyphenol, 4-ethenyl-2-methoxy-phenol, ethyl 3-methylbutanoate, ethyl 3-methylbutanoate and 2-phenylethanol (Gürbüz et al., 2006; Tao et al., 2008). Other authors have shown that the aroma profiles obtained by sensory analysis of Merlot and Cabernet Sauvignon wines from the Bordeaux region were very similar, characterised by high fruity, caramel, green and earthy aroma totals (Kortseridis et al., 2000; Gürbüz et al., 2006). The highest OAV was shown in Pinot noir (ethyl octanoate, 218.72), followed by that in Tempranillo (ethyl octanoate, 42.54), and only the caramel descriptor showed a difference in intensity between the wines. Octanoic acid also made an important contribution to the aroma of all monovarietal wines. However, hexanoic acid only contributed to the aroma of Tempranillo and Pinot noir wines. Hexanoic and octanoic acids are important wine odorants, but they are mostly formed as by products of yeast metabolism, and the contribution of grape precursors is residual from a quantitative point of view (López et al., 2004).

A

Biplot (axes F1 and F2: $69.19 \%$ )

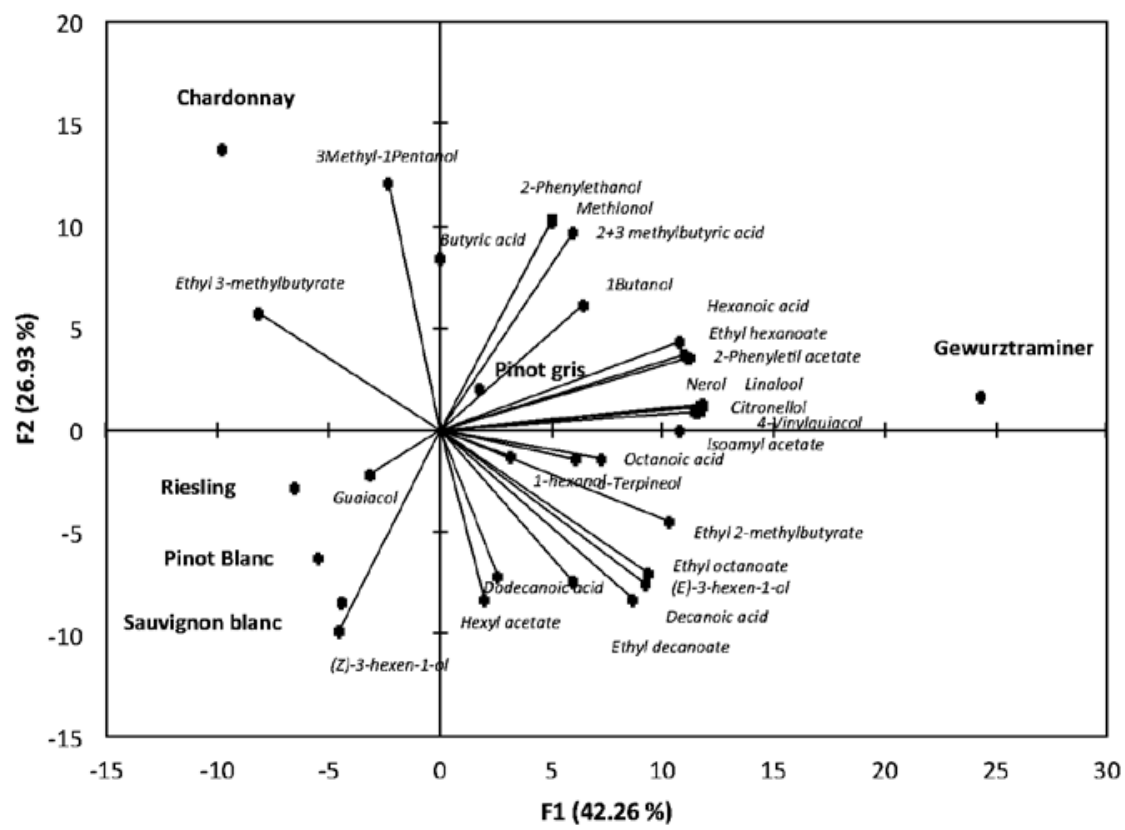

B

Biplot (axes F1 and F2: $90.14 \%$ )

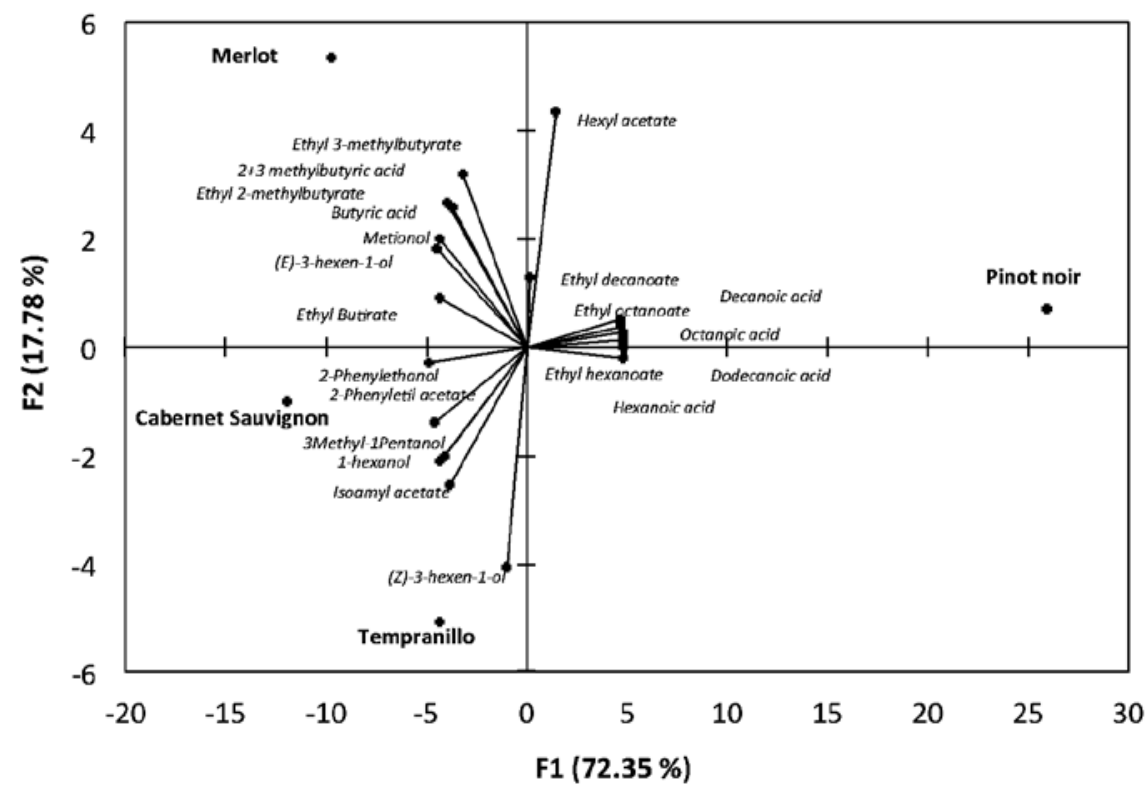

FIGURE 1

Principal component analysis (PCA) based on the volatile composition of A) white wines and B) red wines. 


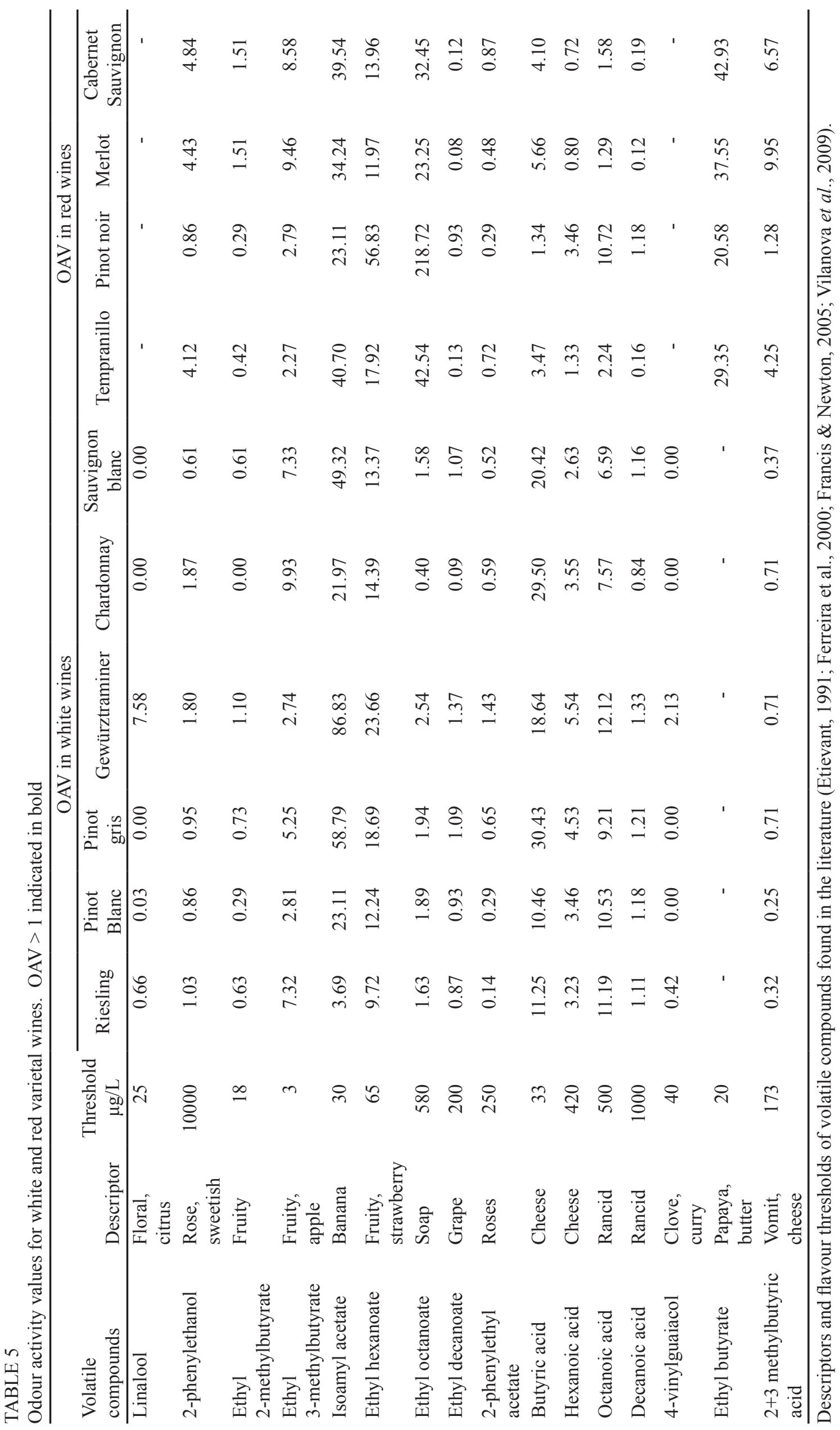




\section{CONCLUSIONS}

The formation of volatile compounds in wines is a complex process and depends on grape composition and the fermentation process. This work provides better knowledge of the volatile composition of wines made from international red and white cultivars (Merlot, Cabernet Sauvignon, Pinot noir, Tempranillo, Sauvignon blanc, Riesling, Chardonnay, Pinot gris, Pinot blanc and Gewürztraminer) grown in NW Spain.

The results obtained show that international cultivars can be characterised and grouped by their volatile composition. Most of the volatiles studied are minor compounds, present in low concentrations. Gewürztraminer showed the highest concentration of volatile compounds. In the red wines the highest concentration of volatile compounds was found in Cabernet Sauvignon, followed by Merlot wines. PCA showed high similarities for the volatile composition of Sauvignon blanc-Pinot blanc-Riesling and Pinot gris grisGewürztraminer in the white wines. Red wines like Cabernet Sauvignon-Tempranillo showed a very similar volatile composition, characterised by alcohols and volatile phenols. According to the $\mathrm{OAV}$, white wines from Gewürztraminer and red wines from Pinot noir showed the highest total value.

\section{LITERATURE CITED}

Agosin, E., Belancic, A., Ibacache, A., Bordeu, E. \& Bayonove, C., 1994. Influencia de la luminosidad e intensidad de carga sobre el potencial aromático de uvas Moscatel rosada y Moscatel de Alejandría. Aconex 46, $3-9$.

Allen, M.S., Lacey, M.J. \& Boyd, S., 1994. Determination of methoxypyrazine in red wine by stable isotope dilution gas chromatographymass spectrometry. J. Agric. Food Chem. 42, 1734-1738.

Arrhenius, S.P., McCloskey, L.P. \& Sylvan, M., 1996. Chemical markers for aroma of Vitis vinifera var. Chardonnay regional wines. J. Agric. Food Chem. 44, 1085-1090.

Berna, A.Z., Trowell, S., Clifford, D., Cynkar, W. \& Cozzolino, D., 2009. Geographical origin of Sauvignon blanc wines predicted by mass spectrometry and metal oxide based electronic nose. Anal. Chem. Acta 648, 146-152.

Bowen, A.J. \& Reynolds, A.G., 2012. Odor potency of aroma compounds in Riesling and Vidal blanc table wines and icewines by gas chromatographyolfactometry-mass spectrometry. J. Agric. Food. Chem. 21, 60(11), 2874 2883 .

Bueno, J.E., Peinado, R., Moreno, J., Medina, M., Moyano, L. \& Zea, L., 2003. Selection of volatile aroma compounds by statistical and enological criteria for analytical differentiation of musts and wines of two grape varieties. J. Food Sci. 68, 158-163.

Cliff, M., Yuksel, D., Girard, B. \& King, M., 2002. Characterization of Canadian ice wines by sensory and compositional analysis. Am. J. Enol. Vitic. 53, 46-50.

Escudero, A., Gogorza, B., Melus, M.A., Ortin, N., Cacho, J. \& Ferreira, V., 2004. Characterization of the aroma of a wine from Macabeo. Key role played by compounds with low odour activity values. J. Agric. Food Chem. 52, 3516-3524.

Etievant, P.X., 1991. Volatile compounds of food and beverages. In: Maarse, H. (ed). Dekker, New York. pp. 483-546.

Falcao, L.D., Revel, G., Rosier, J.P. \& Bordignon, L.M.T., 2008. Aroma impact components of Brazilian Cabernet Sauvignon wines using detection frequency analysis GC-olfactometry. Food Chem. 107, 497-505.
Fang, Y. \& Qian, M.C., 2006. Quantification of selected aroma-active compounds in Pinot noir wines from different grape maturities. J. Agric. Food Chem. 54, 8567-8573.

Ferreira, V., López, R. \& Cacho, J.F., 2000. Quantitative determination of the odorants of young red wines from different grape varieties. J. Sci. Food Agric. 80, 1659-1667.

Francis, I.L. \& Newton, J.L., 2005. Determining wine aroma from compositional data. Aust. J. Grape Wine Res. 11, 114-126.

Gómez, E., Laencina, J. \& Martínez, A., 1994. Vinification effect on changes in volatile compounds of wine. J. Food Sci. 59, 406-409.

Gómez, E., Martínez, A. \& Laencina, J., 1995. Changes in volatile compounds during maturation of some grape varieties. J. Sci. Food Agric. 67, 229-233.

Gómez-Miguez, M.J., Cacho, J.F., Ferreira, V., Vicario, I.M. \& Heredia, F.J., 2007. Volatile components of Zalema white wines. Food Chem. 100, $1464-1473$

Gunata, Y.Z., Bayonove, C.L., Baumes, R.L. \& Cordonnier, R.E., 1985. The aroma of grapes. I. Extraction and determination of free and glycosidically bound fractions of some grape aroma components. J. Chromatograph. A 331, 83-90

Gürbüz, O., Rouseff, J.M. \& Rouseff, R.L., 2006. Comparison of aroma volatiles in commercial Merlot and Cabernet Sauvignon wines using gas chromatography-olfactometry and gas chromatography-mass spectrometry. J. Agric. Food Chem. 54(11), 3990-3996.

Guth, H., 1997. Identification of character impact odorants of different white wine varieties. J. Agric. Food Chem. 45, 3027-3032.

Hejavec, S., Jeromel, A., Da Silva, A., Orlic, S. \& Redzepovic, S., 2007. The quality of white wines fermented in Croatian oak barrels. Food Chem. $100,124-128$.

Jiang, B. \& Zhang, Z., 2010. Volatile compounds of young wines from Cabernet Sauvignon, Cabernet Gernischet and Chardonnay varieties grown in the Loess Plateau Region of China. Molecules 15, 9184-9196.

Komes, D., Ulrich, T. \& Lovric, M. 2006. Characterization of odor-active compounds in Croatian Rhine Riesling wine, subregion Zagorje. Eur. Food Res. Technol. 222, 1-7.

Kortseridis, Y., Razuncles, A., Bertrand, A. \& Baumes, R., 2000. Differentiation of the aromas of Merlot and Cabernet Sauvignon wines using sensory and instrumental analysis. J. Agric. Food Chem. 48(11), 5383-5388.

Lee, S.J. \& Noble, A.C., 2003. Characterization of odor-active compounds in Californian Chardonnay wines using GC-olfactometry and GC-mass spectrometry. J. Agric. Food Chem. 51, 8036-8044.

Li, H., 2006. Wine tasting. China Science Press, Beijing, China.

Li, H., Tao, Y., Wang, H. \& Zhang, L., 2008. Impact odorants of Chardonnay dry white wine from Changli County (China). Eur. Food Res. Technol. 227, 287-292.

López, R., Ezpeleta, E., Sánchez, I., Cacho, J. \& Ferreira, V., 2004. Analysis of the aroma intensities of volatile compounds released from mild acid hydrolysates of odourless precursors extracted from Tempranillo and Grenache grapes using gas chromatography-olfactometry. Food Chem. 88, 95-103.

López, R., Ferreira, V., Hernández, P. \& Cacho, J.F., 1999. Identification of impact odorants of young red wines made with Merlot, Cabernet Sauvignon and Grenache grape varieties: A comparative study. J. Agric. Food Chem. $79,1461-1467$.

Luan, F., Mosandl, A., Gubesch, M., Matthias, M. \& Wüst, M., 2006. Enantioselective analysis of monoterpenes in different grape varieties during berry ripening using stir bar sorptive extraction- and solid phase extraction-enantioselective-multidimensional gas chromatography-mass spectrometry. J. Chromat. A 1112, 369-374. 
Lund, C.M., Thompson, M.K., Benkwitz, F., Wohler, M., Triggs, C.M., Gardner, R., Heymann, H. \& Nicolau, L., 2009. New Zealand Sauvignon blanc distinct flavor characteristics: Sensory, chemical, and consumer aspects. Am. J. Enol. Vitic. 60, 1-12.

Manitto, P., 1980. Biosynthesis of natural products. Ellis Horwood, Chichester.

Marais, J., 1987. Terpene concentrations and wine quality of Vitis vinifera L cv. Gewürztraminer as affected by grape maturity and cellar practices. Vitis 126, 231-245.

Meilgaard, M.C., 1975. Flavour chemistry of beer. Part II: Flavour and threshold of 239 aroma volatiles. MBAA Technology Quart Master Brewing Association 12, 151-168.

OIV, 1990. Recueil des méthodes internacionales d'analyse des vins et des moûts. Office International de la Vigne et du Vin, Paris.

Oliveira, J.M., Araújo, I., Pereira, O.M., Maia, J.S., Amaral, A.J. \& Maia, M.O., 2004. Characterization and differentiation of five "Vinhos Verdes" grape varieties on the basis of monoterpenic compounds. Anal. Chim. Acta $513,269-275$.

Oliveira, J.M., Faria, M., Sá, F., Barros, F. \& Araújo, I.M., 2006. Calcohols as varietal markers for assessment of wine origin. Anal. Chim Acta $563,300-309$.

Oliveira, J.M., Oliveira, P., Baumes, R.L. \& Maia, M.O., 2008. Volatile and glycosidically bound composition of Loureiro and Alvarinho wines. Food Sci. Technol. Int. 14, 341-353.

Perestrelo, R., Fernandes, A., Alburquerque, F.F., Marques, J.C. \& Camara, J.S., 2006. Analytical characterization of the aroma of Tinta Negra Mole red wine: Identification of the main odorants compounds. Anal. Chim. Acta $563,154-164$.

Peter, K., Ong, C. \& Acree, T..E., 1999. Similarities in the aroma chemistry of Gewürztraminer variety wines and lychee (Litchi chinesis Sonn.) fruit. J. Agric. Food Chem. 47(2), 665-670.

Preston, L.D., Block, D.E., Heymann, H., Soleas, G., Noble, A. \& Ebeler, S.E., 2008. Defining vegetal aromas in Cabernet Sauvignon using sensory and chemical evaluations. Am. J. Enol. Vitic. 59, 137-145.
Quian, M.C., Fang, Y. \& Shellie, K., 2009. Volatile composition of Merlot wine from different vine water status. J. Agric. Food Chem. 57, 7459-7463.

Rapp, A., 1998. Volatile flavour of wine: Correlation between instrumental and sensory perception. Nahrung 42, 351-363.

Rapp, A. \& Mandery, H., 1986. Wine aroma. Experientia 42, 873-884.

Robinson, J., 2006 ( $3^{\text {rd }}$ ed). The Oxford companion to wine. Oxford University Press, USA.

Schreier, P., 1979. Flavor composition of wines: a review. CRC Crit. Review Food Sci. Nutr. 12, 59-111.

Shimizu, J., Uehara, M. \& Watanabe, M., 1982. Transformation of terpenoids in grape must by Botrytis cinerea. Agric. Biol. Chem. 46, 1339-1344.

Simpson, R.F., 1979. Some important aroma components of white wine. Food Technol. Aust. 31, 516-522.

Smyth, H.E., Cozzolino, D., Cynkar, W.U., Janik, L., Dambergs, R.G. \& Gishen, M., 2008. Near infrared spectroscopy as a rapid tool to measure volatile aroma compounds in Riesling wine: Possibilities and limits. Anal. Bioanal. Chem. 390(7), 1911-1916.

Swiegers, J.H. \& Pretorius, I.S., 2005. Yeast modulation of wine flavour. Adv. Appl. Microbiol. 57, 131-175.

Tao, Y., Wang, H. \& Zhang, L., 2008. Volatile compounds of young Cabernet Sauvignon red wine from Chagli County (China). J. Food Comp. Anal. 21, 689-694

Versini, G., Carlin, S., Nicolini, G., Dellacassa, E. \& Carrau, F., 1999. Updating of varietal aroma components in wines. Vitiviniculture in the Southern hemisphere: Proc. $7^{\text {th }}$ Latin-America Congress of Vit. and Winemaking, Mendoza, Argentina. pp. 325 - 349.

Vilanova, M. \& Sieiro, C., 2006. Determination of free and bound compounds in Albariño wine. J. Food Comp. Anal. 19, 694-697.

Vilanova, M. \& Sieiro, C., 2007. Effect of terroir on the volatiles of Vitis vinifera cv. Albariño. J. Sci. Food Agric. 87, 1252-1256.

Vilanova, M., Masa, A. \& Tardaguila, J., 2009. Evaluation of the aromatic variability of Spanish grape by quantitative descriptive analysis. Euphytica $165,383-389$. 